\title{
Comparación de náuseas y vómitos postoperatorios en cirugías mamarias: anestesia balanceada vs triple terapia
}

\author{
Romero JEO.1, Molinelli M. ${ }^{1}$, Uranga S. ${ }^{1}$ \\ 1 Hospital Interzonal General de Agudos "Dr. Óscar E. Alende", Mar del Plata, Argentina. \\ Introducción: Las náuseas y los vómitos postoperatorios (NVPO) son una complicación frecuente de la anestesia y la \\ cirugía, estimándose su incidencia en un $25-30 \%$ de los pacientes. Más aún, en pacientes de alto riesgo, su incidencia \\ alcanza un $70-80 \%$.
}

Algunos de los factores de riesgo más importantes que predisponen a presentar NVPO son: el sexo femenino, menor edad, ser no tabaquista, el historial de NVPO o de cinetosis, uso de opioides y la anestesia balanceada. Las NVPO pueden estar asociados con muchas complicaciones (broncoaspiración, deshidratación, dehiscencia de herida, etc.).

El objetivo del presente trabajo es comparar la incidencia de náuseas y vómitos postoperatorios, en cirugías de mama utilizando anestesia balanceada vs triple terapia en pacientes con un valor en la escala de Apfel de 4 en el Hospital Interzonal General de Agudos "Dr. Óscar E. Alende” de Mar del Plata, Argentina, durante el período 2018-2019.

Materiales y Métodos: Se realizó un estudio comparativo, desde septiembre de 2018 a marzo de 2019. Se incluyeron 26 mujeres con edades entre los 23 y los 79 años, sometidas a cirugías mamarias con escala de Apfel de 4, se excluyeron pacientes masculinos o que usaban antieméticos o que presentaban náuseas o vómitos previos por alguna patología orgánica. Se dividieron los pacientes de forma aleatorizada en dos grupos: anestesia balanceada y triple terapia, quedando en cada uno 13 pacientes. Se analizaron incidencias de NVPO (30', 6 y 24 h) y sus asociaciones con diferentes factores de riesgos.

Resultados: Del total de los 26 pacientes incluidos en el estudio, 19 de ellos presentaron náuseas y vómitos postoperatorios. Es decir que la incidencia de NVPO en nuestra población fue de 73\%; al analizar los grupos por separados, los pacientes del grupo anestesia balanceada tuvieron una incidencia de NVPO de $92 \%$ comparado con el grupo de triple terapia en el que fue de $53 \%$. En los primeros 30 minutos posoperatorios, 12/13 personas del grupo que recibió anestesia balanceada tuvieron NVPO, comparado con $7 / 13$ del grupo triple terapia (p valor: 0,0052 , OR: 10,2, IC: 1,01-103).

Conclusiones: La incidencia de NVPO en pacientes con un apfel de 4 es elevada. El uso de técnica balanceada o triple terapia cambia significativamente los resultados, en especial en la incidencia de NVPO de los primeros 30 minutos posquirúrgicos. La cinetosis fue el factor de riesgo más determinante en la reiteración de los episodios de NVPO durante el transcurso del día posquirúrgico.

https://doi.org/10.25237/congresoclasa2019.11 